\title{
Mancha areolada de Thanatephorus da seringueira na Amazônia: identificação filogenética e variação genética em populações do patógeno
}

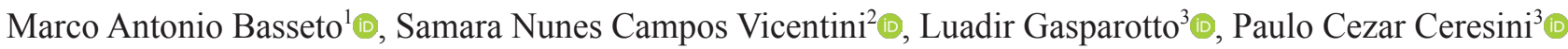

${ }^{1}$ Coordenadoria de Defesa Agropecuária, Escritório de Defesa Agropecuária (EDA) de Araçatuba, Av. Governador Mário Covas 2600, CEP 16072-005, Araçatuba, SP, Brasil. Tel. +55 (18)3624-5264. ${ }^{2}$ Universidade Estadual Paulista (UNESP), Campus de Ilha Solteira, Departamento de Fitossanidade, Engenharia Rural e Solos, CEP 15385-000, Ilha Solteira, SP, Brasil. Tel. +55(18)3743-1142. ${ }^{3}$ Empresa Brasileira de Pesquisa Agropecuária, Embrapa Amazônia Ocidental, Rod. AM-010 km 29 (Estr. Manaus/Itacoatiara), CP 319, CEP 69010-970, Manaus, AM, Brasil. Autor para correspondência: Paulo Cezar Ceresini (paulo.ceresini@unesp.br)

Data de chegada: 11/09/2017. Aceito para publicação em: 04/02/2019.

$10.1590 / 0100-5405 / 185131$

\section{RESUMO}

Basseto, M.A.; Vicentini, S.N.C.; Gasparotto, L.; Ceresini, P.C. Mancha areolada de Thanatephorus da seringueira na Amazônia: identificação filogenética e variação genética em populações do patógeno. Summa Phytopathologica, v.45, n.3, p.285-294, 2019.

A mancha areolada de Thanatephorus é uma das doenças mais importantes da seringueira (Hevea brasiliensis) na Amazônia. Apesar disso, questão importante sobre o real posicionamento filogenético deste patógeno ainda não foi respondida. Neste estudo, nós analisamos os padrões de variação genética em seqüências da região ITS-5.8S do rDNA de uma população de $T$. cucumeris (fase assexuada = Rhizoctonia solani AG 2-2) associado à mancha areolada da seringueira amostrada em Belém (Pará), Manaus (Amazonas) e Xapuri/Rio Branco (Acre) na Amazônia, e comparando-a filogeneticamente com membros do complexo AG 2 descritos mundialmente. Este estudo representa um passo importante para revelar a etiologia da fase assexuada de T. cucumeris da seringueira. Filogeneticamente, por análise Bayesiana, encontramos suporte para nomear um novo grupo de anastomose de R. solani associado à mancha areolada da seringueira: o AG 2-2 Hb. Este grupo constitui-se numa unidade evolutiva independente em relação aos subgrupos mundiais do AG 2-2 analisados. Na genealogia gênica construída por análise coalescente, observou-se que a população de R. solani AG 2-2 Hb de Belém é relativamente mais velha que as demais populações analisadas. O ancestral comum de todas as três populações analisadas está associado com a mancha foliar do maracujazeiro (Passiflora edulis), em Belém e tem cerca de 0,8 unidades evolutivas coalescentes de idade. Nenhum haplótipo da região ITS-5.8S do AG 2-2 Hb de Belém foi observado em outras regiões. Entretanto, a população de Manaus compartilhou dois, de seus quatro haplótipos, com aqueles observados em Xapuri / Rio Branco, no Acre, indicando fluxo gênico.

Palavras-chave: Rhizoctonia solani, grupos de anastomose, DNA ribossomal, Thanatephorus cucumeris.

\section{ABSTRACT}

Basseto, M.A.; Vicentini, S.N.C.; Gasparotto, L.; Ceresini, P.C. Thanatephorus target spot on rubber tree in the Amazon: phylogenetics and genetic variation in populations of the pathogen. Summa Phytopathologica, v.45, n.3, p.285-294, 2019.

Thanatephorus target spot is one of the most important diseases of rubber tree (Hevea brasiliensis) in the Amazon. However, an important question about the actual phylogenetic placement of this pathogen has not been answered yet. In this study, we analyzed the patterns of genetic variation in sequences of the ITS-5.8S rDNA region from a population of T. cucumeris (asexual phase $=$ Rhizoctonia solani AG 2-2) associated with the rubber tree target spot sampled in Belém (Pará), Manaus (Amazonas) and Xapuri/Rio Branco (Acre), phylogenetically comparing with worldwide described members of AG 2. This study represents an important step to reveal the etiology of the asexual phase of T. cucumeris in the rubber tree. Phylogenetically, based on Bayesian analyses, we found support to nominate a new group of $R$. solani anastomosis associated with rubber tree target spot: AG 2-2 $\mathrm{Hb}$. This group consisted of an independent evolutionary unit in relation to the worldwide described sub-groups of $A G$ 2-2. Considering the gene genealogy built by coalescent analysis, we observed that the population of $R$. solani AG 2-2 Hb from Belém was relatively older than the other two analyzed populations. The common ancestor of all three populations is associated with passion-fruit (Passiflora edulis) foliar blight in Belém and has about 0.8 coalescent evolutionary units of age. No haplotype of the ITS-5.8S region of AG 2-2 $\mathrm{Hb}$ from Belém was observed in any other region. However, the population from Manaus shared two of its four haplotypes with those observed in Xapuri/Rio Branco, Acre, indicating gene flow.

Keywords: Rhizoctonia solani, anastomosis groups, ribosomal DNA, Thanatephorus cucumeris.

Sob condições naturais, Thanatephorus cucumeris (Frank) Donk [fase assexuada $=$ Rhizoctonia solani $\mathrm{Kühn}]$ causa várias doenças foliares em culturas de importância agrícola ou espécies nativas na região Amazônica do país (9). Entre as doenças relatadas, a mancha areolada da seringueira [Hevea brasiliensis (Willd. ex A.Juss.) Müll. Arg] é uma das mais importantes para a espécie da região $(11,13)$. A infecção das plantas de seringueira ocorre por meio de basidiósporos produzidos por T. cucumeris e que podem ser disseminados a longas distâncias $(15,23)$.

A mancha areolada da seringueira foi relatada pela primeira vez no Brasil em 1943 no Pará (11). Apesar de já ser conhecida há algum tempo, a doença só passou a causar danos à cultura a partir da década de 70, com o aumento das áreas de cultivo racional da seringueira na Amazônia (12). O patógeno afeta todas as espécies de Hevea $(8,10,11)$. A maioria dos clones brasileiros de seringueira é considerada suscetível à mancha areolada (15). Em estudo realizado 
com 70 clones orientais e 34 clones nacionais, observou-se que todos os clones foram suscetíveis ou altamente suscetíveis à mancha areolada. Entretanto, na Costa Rica, há relato de resistência em Hevea brasiliensis (clones FB 54 e FB 3363), Hevea benthamiana (clones F4515, F4327 e F4542), Hevea pauciflora e Hevea rigidifolia (8).

Muito embora uma série de pesquisas tenha sido desenvolvida para compreender aspectos relativos à epidemiologia e manejo da mancha areolada da seringueira, até 2010 a etiologia do patógeno ainda não estava completamente clara. O único relato etiológico clássico da literatura data da década de 80 quando Bolkan \& Ribeiro (5) determinaram, com base em reações de anastomose, que o AG 2 estava consistentemente associado à mancha areolada da seringueira no Amazonas. Naquela época, entretanto, apenas cinco grupos de anastomose de $R$. solani haviam sido descritos mundialmente. Muitos outros grupos e subgrupos de anastomose foram descritos desde então.

Em 2010, por meio de reconstrução filogenética, Gaino et al. (13) confirmaram que $R$. solani AG 2 estava associado à mancha areolada da seringueira na Amazônia porém os isolados de seringueira eram divergentes dos demais membros do AG 2 descritos mundialmente, os quais incluíram: AG 2-1, AG 2-2 IIIB, AG 2-2 IV, AG 2-2 LP e AG 2-3 (7). Isolados de outros AGs de $R$. solani tais como AG 1 ID, IF [recentemente reclassificados de IB (14)] e de Rhizoctonia sp. binucleada (AG R, associado à fase sexuada de Ceratobasidium), oriundos de hospedeiros distintos, também infectaram seringueira (13).

Para esclarecer questão etiológica importante, o primeiro objetivo deste estudo foi determinar o posicionamento filogenético de uma população de isolados de $R$. solani AG 2 da seringueira amostrada na Amazônia em relação a membros do AG 2 descritos mundialmente. Para tanto foram analisadas seqüências da região ITS-5.8S do rDNA de 146 isolados do patógeno amostrados em três populações geográficas obtidas nos estados do Pará, do Amazonas e do Acre, na Amazônia Brasileira.

O segundo objetivo deste estudo foi descrever os padrões evolutivopopulacionais da variação genética observada na região ITS-5.8S do rDNA de $R$. solani AG 2 associado à mancha areolada da seringueira nas três populações geográficas amostradas. Por tratar-se de patógeno cuja reprodução sexuada é importante no ciclo biológico da doença, nossa hipótese é que populações de $R$. solani AG 2 da seringueira no Amazonas apresentam altos níveis de variação genética. Pelo isolamento geográfico das três populações amostradas do patógeno (separadas por um transecto de até $2800 \mathrm{~km}$ ), postulamos, que essas populações são diferenciadas geneticamente e consequentemente, subdividas.

\section{MATERIAL E MÉTODOS}

\section{Amostragem}

Para o estudo sobre a etiologia do patógeno da mancha areolada da seringueira e sobre aspectos evolutivos da variação genética na região ITS-5.8S do rDNA de $T$. cucumeris (i.e., $R$. solani AG 2-2) da seringueira, amostrou-se 33 plantas infectadas nos municípios de Rio Branco/Xapuri no Acre (latitude $11^{\circ} 01,777^{\prime} \mathrm{S}$, longitude $\left.68^{\circ} 43,923^{\prime} \mathrm{O}\right), 68$ em Manaus no Amazonas $\left(02^{\circ}\right.$ $\left.53,461^{\prime} \mathrm{S}, 59^{\circ} 58,491^{\prime} \mathrm{O}\right)$ e 43 em Belém no Pará $\left(01^{\circ} 26.414^{\prime} \mathrm{S}, 48^{\circ} 26.766^{\prime}\right.$ O), em Janeiro de 2005 (Figura 1). Obteve-se 144 isolados de T. cucumeris da seringueira e dois de maracujazeiro (de Benevides, próximo a Belém, PA).

\section{Isolamento do patógeno}

Para o isolamento do patógeno, fragmentos de lesões foliares foram inicialmente desinfestadas pela imersão em solução de álcool $70 \%$, hipoclorito de sódio a $1 \%$ e lavados duas vezes em água destilada e esterilizada. Após este procedimento, os tecidos vegetais foram transferidos para placas de Petri contendo meio de cultura ágar-água (AA) alcalino, $\mathrm{pH} 8,5$ e após 24 h para o meio de batata-dextrose-ágar (BDA). Os isolados obtidos de plantas de seringueira foram preservados em grãos de arroz parboilizado, segundo metodologia modificada de Sneh et al. (27) e mantidos à temperatura de $-20^{\circ} \mathrm{C}$.

\section{Extração do DNA genômico}

De cada isolado de T. cucumeris foi produzido micélio em $25 \mathrm{ml}$ de CBD (caldo de batata dextrose) contendo $50 \mu \mathrm{g}$ de kanamicina. $\mathrm{mL}^{-1}$. As culturas foram incubadas a $25^{\circ} \mathrm{C}$, com agitação. $\mathrm{O}$ micélio foi coletado após cinco dias de incubação, sendo então congelado e liofilizado. O DNA total foi extraído do micélio liofilizado utilizando-se o kit de extração DNeasy Plant Mini Extraction Kit® (Qiagen, Alemanha), de acordo com recomendação do fabricante.

\section{Amplificação e sequenciamento da região ITS do rDNA}

Procedeu-se a reações de polimerase em cadeia (PCR) para a amplificação da região ITS1-5.8S-ITS2 do DNA ribossomal (rDNA) utilizando $25 \mathrm{ng}$ de DNA fúngico por reação e condições semelhantes às descritas por Gonzalez
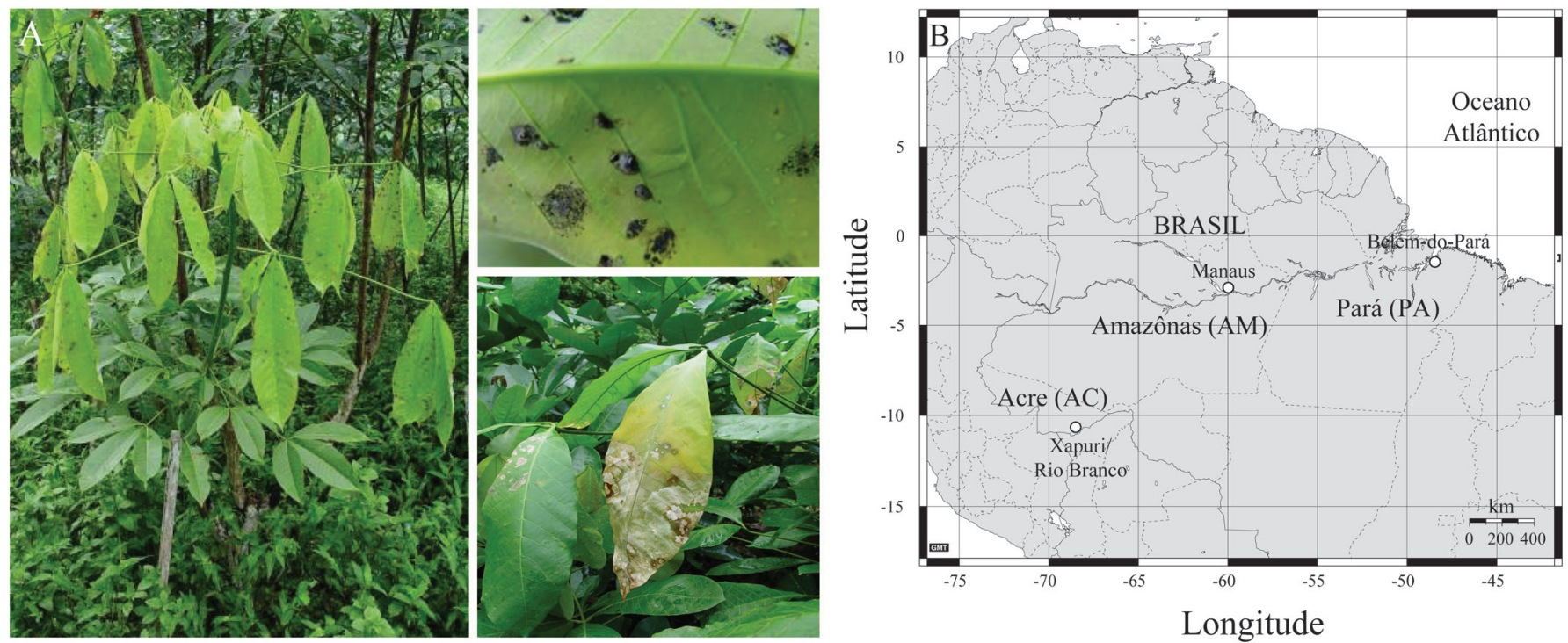

Figura 1. Sintomas de mancha areolada da seringueira em brotações jovens de clone suscetível, com detalhes de exudação de látex na face inferior das folhas e lesões necróticas severas no limbo foliar (A). Representação das áreas geográficas de onde se amostrou três populações do patógeno nos estados do Acre, do Amazonas e do Pará (B). 
et al. (16). Amplificações foram efetuadas usando-se o conjunto de iniciadores (primers) ITS4/ITS5 (30). Cada produto de PCR foi purificado utilizando-se colunas MicroSpin S-400 HR (GE Healthcare, EUA), de acordo com instruções do fabricante. No seqüenciamento do operon ITS1-5.8S-ITS2 rDNA amplificado foi utilizado o kit pré-misturado BigDye TM Terminator v3.1 Cycle Sequencing Kit (Thermo Fisher Scientific, EUA) para ciclo de sequencimento baseado em química de corante terminador, conforme instruções do fabricante. Cerca de 75 ng de DNA amplificado foram utilizados por reação e um $\mu \mathrm{M}$ de cada um dos iniciadores ITS4 ou ITS5 em reações independentes para cobertura completa dos fragmentos. Os produtos de sequenciamento foram separados por sequenciamento capilar usando polímero POP $7{ }^{\mathrm{TM}}$ Polymer (Thermo Fisher Scientific, EUA) no analisador genético automático ABI 3130 (Applied Biosystems, EUA). As seqüências obtidas foram analisadas no programa Sequencher ${ }^{\text {TM }} 4.1$ (GeneCodes, USA), para avaliação da qualidade e montagem de contigs dos fragmentos, e alinhadas no programa computacional "ClustalX" (29).

\section{Análise de dados}

Inicialmente, para confirmar que o grupamento de anastomose dos isolados de T. cucumeris (R. solani) da seringueira pertencem ao AG 2-2, as sequências obtidas foram comparadas com sequências da região ITS do rDNA dos grupos de anastomose AG 2-1, AG 2-2 (IIIB, IV e LP) e AG 2-3 depositadas no banco de dados do NCBI/GenBank. As comparações de similaridade entre estas sequências foram obtidas por BLASTn (nucleotídeo-nucleotídeo), versão de 08/09/2016, disponível no site https://blast.ncbi.nlm.nih.gov/Blast. cgi?PAGE=Nucleotides (21).

\section{Análise filogenética}

As relações filogenéticas entre haplótipos da região ITS-5.8S do rDNA dos isolados de T. cucumeris da seringueira foram determinadas por análise Bayesiana usando o método de Monte Carlo - Cadeia de Markov, conjugado ao algoritmo de Metropolis (MCMCMC), usando o programa MrBayes v 2.01 (20). Foram incluídas na análise seqüências do ITS rDNA dos grupos de anastomose AG 2-1, AG 2-2 (IIIB, IV e LP) e AG 2-3 de R. solani depositadas no banco de dados do NCBI/GenBank. (Tabela 1).

Para a análise de MCMCMC, MODELTEST 3.7 (25) (implementado no programa PAUP4* (34)) foi utilizado para determinar o modelo de substituição de bases de DNA que mais se ajustou aos dados. Um teste hierárquico da razão da verossimilhança implementado no MODELTEST selecionou o modelo GTR +I (proporção de sítios invariáveis $=0$; frequência de bases $A=0.2266, C=0.2745$; $\mathrm{G}=0.1684 \mathrm{e} \mathrm{T}=0.3304$; parâmetro da distribuição gama $=0.2303$ ). Sob este modelo evolutivo, o valor de ML da árvore mais provável foi de $-\operatorname{lnL}=843.13$. A análise filogenética por MCMCMC foi executada usando como hipótese $a$ priori o modelo de substituição de bases de DNA acima descrito. Procurou-se por 3.000.000 de gerações usando-se quatro cadeias de buscas, eliminando-se as primeiras 250 árvores, e armazenando-se uma árvore a cada 500. Valores de probabilidade posterior (PP) para as ramificações da árvore consenso foram gerados considerando-se a regra de no mínimo 50\% do total de 11542 árvores apresentarem a respectiva ramificação.

\section{Teste de subdivisão populacional e análise de coalescência}

Para cada população amostrada (Xapuri/Rio Branco, Manaus e Belém) foi estimado o valor de $\Theta$ (taxa de mutação populacional), baseando-se no número de sítios segregantes $s$ para a região ITS-5.8S do rDNA. Para testar-se diferenciação populacional utilizou-se SNAP Map [algorítimo implementado no programa SNAP Workbench, disponível como plataforma de análise evolutiva na rede $(2,22)$ ] para gerar os arquivos apropriados de seqüências, Seqtomatrix (18) para converter o arquivo de sequências numa matriz de distancias e Permtest (19) para testar a subdivisão geográfica em amostras de DNA para duas ou mais localidades. É necessário testar-se a hipótese de que não há diferenciação genética para determinar se assumimos o modelo de população panmítica ou subdividida, para então examinarmos a divergência de populações usando Genetree (3), também implementado pelo programa SNAP Workbench. O programa MIGRATE (4), implementado no SNAP Workbench foi utilizado para estimar taxas de migração na história ancestral das populações. Agenealogia com a maior probabilidade de enraizamento, e o tempo desde o mais recente ancestral comum (TCMR) da amostra foi estimada pelas simulações coalescentes. As posições (i.e., tempo para coalescência) das mutações dando origem à alterações/ substituições na região estudada foram determinadas.

\section{RESULTADOS E DISCUSSÃO}

Os 140 isolados obtidos de seringueira apresentaram sequências da região ITS-5.8S do rDNA similares (por BLASTn) às sequências do grupo de anastomose AG 2-2 (IV) de R. solani, consistente com os dados da literatura sobre a associação do AG 2-2 à mancha areolada da seringueira (6). Dois isolados obtidos de maracujazeiro na região de Benevides, próximo a Belém, no Pará, também foram caracterizados como AG 2-2.

Numa etapa seguinte, buscou-se determinar a composição e diversidade de haplótipos (sequências únicas da região ITS-5.8S do rDNA dos indivíduos amostrados) associados com a mancha areolada da seringueira e do maracujazeiro na Amazônia brasileira, bem como comparar com os haplótipos mundiais depositados no NCBI/GenBank. Para um total de 146 isolados do patógeno analisados, apenas oito haplótipos distintos da região ITS-5.8 rDNA foram observados. De forma bastante peculiar, nenhum dos oito haplótipos identificados na amostra de T. cucumeris da Amazônia brasileira foi similar a haplótipos do grupo de anastomose AG 2-2 IV identificados no resto do mundo. De forma global, no total, 22 haplótipos da região ITS-5.8S do rDNA do AG 2-2 IV foram caracterizados no mundo: oito brasileiros e 14 do resto do mundo (Tabela 1). Optou-se por utilizar uma nomenclatura para os haplótipos mundiais (incluindo os brasileiros) do AG 2, que variou de de $\mathrm{H} 01$ a H47, e outra nomenclatura distinta apenas para os haplótipos brasileiros usados na análise de coalescência (variando de $\mathrm{A} \mathrm{a} \mathrm{H}$ ).

Cem mutações, ao longo de 742 pares de base (pb) analisados, caracterizaram os diferentes haplótipos da amostra mundial de $R$. solani AG 2 (subgrupos 2-1, 2-2 IIIB, IV, LP, de isolados de H. brasiliensis, e do 2-3). Analisando-se apenas o AG 2-2 IV, quarenta e seis mutações (num total de 662 $\mathrm{pb}$ analisados) caracterizam as diferenças entre os 22 haplótipos identificados mundialmente. Quando apenas a amostra brasileira do AG 2-2 associado com H. brasiliensis ou com P. edulis foi analisada (Tabela 2), o número de mutações de ponto observadas ao longo da região ITS-5.8S diminuiu para 11 , no total. Os haplótipos mais frequentes na população Amazônica foram B (31.8\%), E $(25,0 \%)$ e A (18.9\%). Já os menos frequentes foram o C, D e H, representado, cada um, apenas $1.4 \%$ do total da amostra (Tabela 2).

Considerou-se significativo o número de mutações separando os haplótipos Amazônicos do ITS-5.8S rDNA de isolados de T. cucumeris de H. brasiliensis e de $P$. edulis dos demais haplótipos mundiais do AG 2-2 IV (35 mutações, ou $5,3 \%$ do total de sítios analisados). Este nível de variação gênica num marcador é suficiente a separação entre duas espécies filogenéticas (28). Neste ponto de nosso estudo, questionamos se, de fato, todos os isolados brasileiros associados com a mancha areolada da seringueira pertencem ao AG 2-2 IV, como relatado no passado por Bolkan \& Ribeiro (5).

Construiu-se então, árvore filogenética da região ITS-5.8S do rDNA, baseada em análise Bayesiana, para representar as relações filogenéticas entre os haplótipos Amazônicos em comparação com haplótipos do AG 2-1, AG 2-2 (IIIB, IV e LP) e AG 2-3 (Figura 2). Todos os haplótipos Amazônicos amostrados foram agrupados num único clado com suporte estatístico (probabilidade posterior) máximo $(=1,00)$. O clado dos haplótipos ITS-5.8S rDNA brasileiros está relacionado com o AG 2-2 de $R$. solani, mas é uma unidade evolutiva 
Tabela 1. Haplótipos de Rhizoctonia solani AG 2 (dos subgrupos 2-1, 2-2 IIIB, IV e LP, e 2-3, e aqueles associados a Hevea brasiliensis) determinados com base em polimorfismos detectados em seqüências de DNA da região ITS1-5.8S-ITS2 do rDNA.

\begin{tabular}{|c|c|c|c|c|c|c|c|c|c|}
\hline $\begin{array}{l}\text { Haplótipos } \\
\text { mundiais } \\
\text { (filogenia) }\end{array}$ & 吾 & $\begin{array}{l}\text { Haplótipos } \\
\text { brasileiros } \\
\text { (análise } \\
\text { coalescente) }\end{array}$ & 吾 & $\begin{array}{c}\text { Grupo de } \\
\text { anastomose }\end{array}$ & $\begin{array}{c}\text { Código } \\
\text { da } \\
\text { sequência } \\
\text { no NCBI/ } \\
\text { GenBank } \\
\end{array}$ & Isolados & Hospedeiro & $\begin{array}{l}\text { Local de } \\
\text { origem }\end{array}$ & Fonte* \\
\hline \multicolumn{10}{|c|}{ Amostra da Amazônia Brasileira } \\
\hline \multirow[t]{2}{*}{ H1 } & 62 & $\mathrm{~B}$ & 45 & AG 2-2 $\mathrm{Hb}$ & MN421919 & 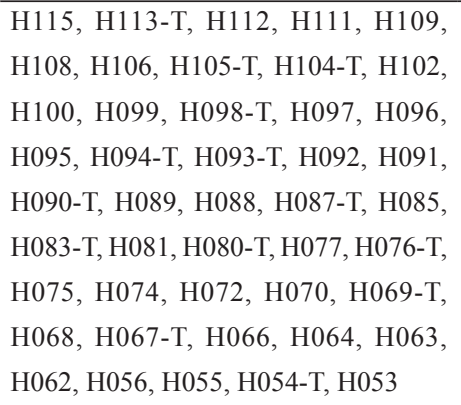 & $\begin{array}{c}\text { Hevea } \\
\text { brasiliensis }\end{array}$ & $\begin{array}{l}\text { Brasil, } \\
\text { Amazonas, } \\
\text { Manaus }\end{array}$ & P. C. Ceresini \\
\hline & & $\mathrm{F}$ & 15 & AG 2-2 Hb & MN421918 & $\begin{array}{l}\text { H054-C, H067-C, H069-C, H076-C, } \\
\text { H080-C, H083-C, H084, H087-C, } \\
\text { H090-C, H093-C, H094-C, H098-C, } \\
\text { H104-C, H105-C, H113-C }\end{array}$ & H. brasiliensis & $\begin{array}{l}\text { Brasil, } \\
\text { Amazonas, } \\
\text { Manaus }\end{array}$ & P. C. Ceresini \\
\hline $\mathrm{H} 43$ & 02 & $\mathrm{D}$ & 02 & AG $2-2 \mathrm{Hb}$ & MN421917 & H057, H073 & H. brasiliensis & $\begin{array}{l}\text { Brasil, } \\
\text { Amazonas, } \\
\text { Manaus }\end{array}$ & P. C. Ceresini \\
\hline $\mathrm{H} 44$ & 13 & G & 13 & AG 2-2 $\mathrm{Hb}$ & MN421916 & $\begin{array}{l}\text { H119, H121, H122, H123, H132, H134, } \\
\text { H135, H142, H150, H154, H155, H158, } \\
\text { H160 }\end{array}$ & H. brasiliensis & $\begin{array}{l}\text { Brasil, Pará, } \\
\text { Belém }\end{array}$ & P. C. Ceresini \\
\hline H46 & & A & 28 & AG $2-2 \mathrm{Hb}$ & MN421912 & $\begin{array}{l}\text { H013, H116, H117, H118, H124, H126, } \\
\text { H128, H129, H130, H133, H136, H137, } \\
\text { H138, H139, H140, H141, H143, H145, } \\
\text { H146, H148, H149, H151, H152, H153, } \\
\text { H156, H157543T, H159543T, H161 }\end{array}$ & H. brasiliensis & $\begin{array}{l}\text { Brasil, Pará, } \\
\text { Belém }\end{array}$ & P. C. Ceresini \\
\hline H47 & 02 & $\mathrm{H}$ & 02 & AG $2-2 \mathrm{Hb}$ & MN421911 & H157543C, H159543C & H. brasiliensis & $\begin{array}{c}\text { Brasil, Pará, } \\
\text { Belém }\end{array}$ & P. C. Ceresini \\
\hline
\end{tabular}

...Continua 
Tabela 1. Continuação

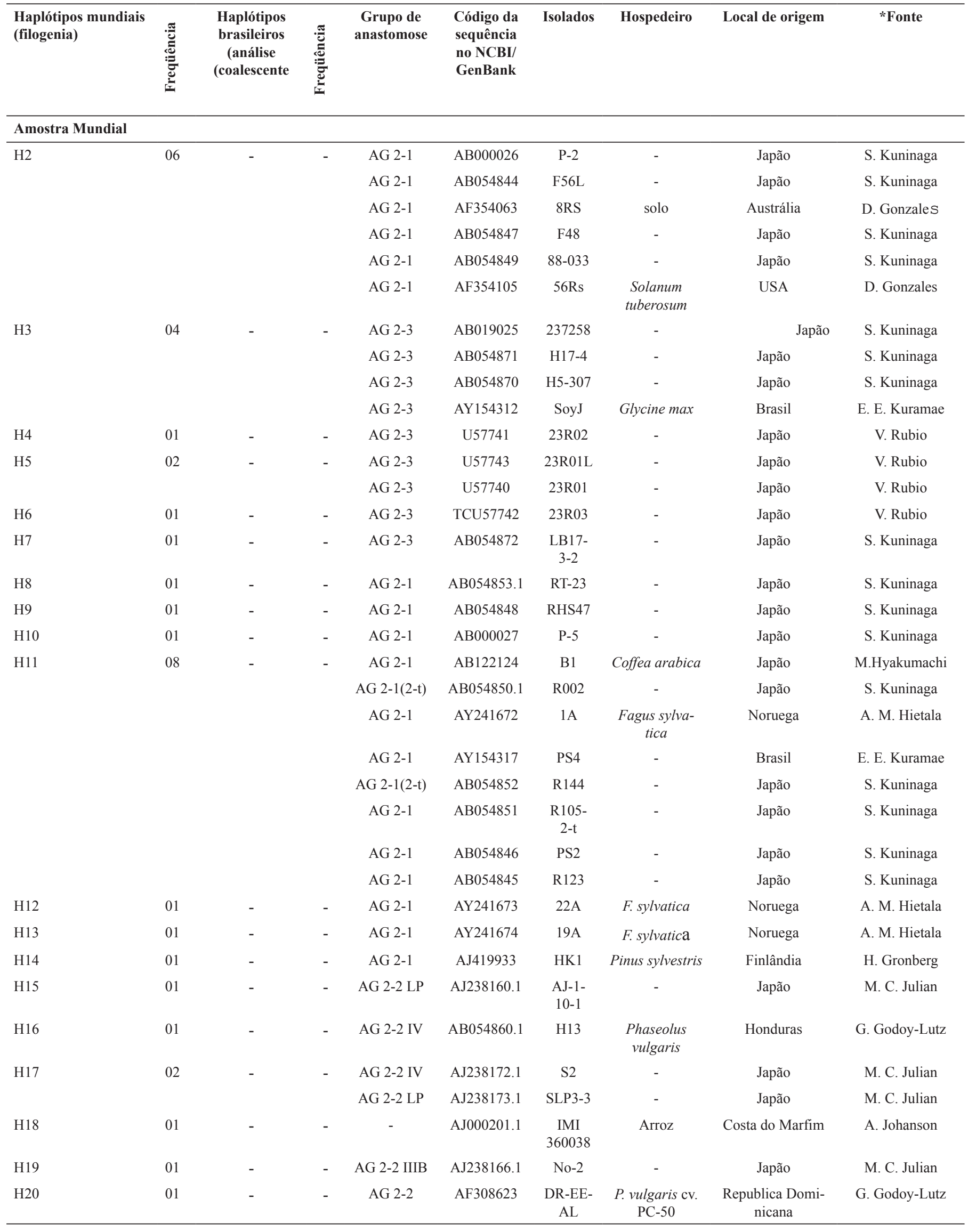


Tabela 1. Continuação

\begin{tabular}{|c|c|c|c|c|c|c|c|c|c|}
\hline $\begin{array}{l}\text { Haplótipos mundiais } \\
\text { (filogenia) }\end{array}$ & 音 & $\begin{array}{l}\text { Haplótipos } \\
\text { brasileiros } \\
\text { (análise } \\
\text { (coalescente }\end{array}$ & 吾 & $\begin{array}{c}\text { Grupo de } \\
\text { anastomose }\end{array}$ & $\begin{array}{l}\text { Código da } \\
\text { sequência } \\
\text { no NCBI/ } \\
\text { GenBank }\end{array}$ & Isolados & Hospedeiro & Local de origem & *Fonte \\
\hline $\mathrm{H} 21$ & 03 & - & - & AG 2-2 IV & AB054859.1 & $\begin{array}{l}87-24- \\
4 \mathrm{~A}\end{array}$ & Beta vulgaris & EUA, Minnesota & S. Kuninaga \\
\hline $\mathrm{H} 22$ & 01 & - & - & AG 2-2 IV & AJ238168.1 & R64 & - & Japão & M. C. Julian \\
\hline $\mathrm{H} 23$ & 01 & - & - & AG 2-2 IV & AB054864.1 & $\mathrm{W}-22$ & P. vulgaris & EUA, Wisconsin & S. Kuninaga \\
\hline $\mathrm{H} 24$ & 01 & - & - & AG 2-2 IV & AB054865.1 & RI-64 & B. vulgaris & Japão & S. Kuninaga \\
\hline $\mathrm{H} 25$ & 01 & - & - & AG 2-2 IV & AJ238164.1 & $\mathrm{K}-1$ & - & Japão & M. C. Julian \\
\hline $\mathrm{H} 28$ & 01 & - & - & AG 2-2 IV & AB054861.1 & DR-G02 & P. vulgaris & $\begin{array}{l}\text { Republica Domi- } \\
\text { nicana }\end{array}$ & S. Kuninaga \\
\hline \multirow[t]{2}{*}{$\mathrm{H} 29$} & 02 & - & - & AG 2-2 LP & AJ238171.1 & RGR39 & - & Japão & M. C. Julian \\
\hline & & & & AG 2-2 LP & AJ238170.1 & RGR38 & - & Japão & M. C. Julian \\
\hline $\mathrm{H} 30$ & 01 & - & - & AG 2-2 IV & AB054863.1 & R9 & B. vulgaris & EUA, Colorado & S. Kuninaga \\
\hline H31 & 01 & - & - & AG 2-2 LP & AJ238165.1 & L-9-1S & - & Japão & M. C. Julian \\
\hline H32 & 01 & - & - & AG 2-2 IIIB & AY270015.1 & SJ07 & G. $\max$ & Brasil & R. C. Fenille \\
\hline \multirow[t]{2}{*}{$\mathrm{H} 33$} & 03 & - & - & AG 2-2 LP & AB054867.1 & G4 & $\begin{array}{l}\text { Zoysia tenui- } \\
\quad \text { folia }\end{array}$ & Japão & S. Kuninaga \\
\hline & & & & AG 2-2 LP & AB054868.1 & G8 & Z. tenuifolia & Japão & S. Kuninaga \\
\hline H37 & 01 & - & - & AG 2-2 IIIB & AB054857.1 & $89-21-4$ & Zea mays & EUA & S. Kuninaga \\
\hline $\mathrm{H} 38$ & 01 & - & - & AG 2-2 IIIB & AJ238162.1 & C-306 & - & Japão & M. C. Julian \\
\hline H39 & 01 & - & - & AG 2-2 IIIB & AB054855.1 & $87-36-1$ & P. vulgaris & $\begin{array}{l}\text { EUA, North } \\
\text { Dakota }\end{array}$ & S. Kuninaga \\
\hline $\mathrm{H} 40$ & 01 & - & & AG 2-2 IIIB & AB054854.1 & $\mathrm{C} 96 \mathrm{~J}$ & Juncus effusus & Japão & S. Kuninaga \\
\hline $\mathrm{H} 41$ & 01 & - & - & AG 2-2 IIIB & AF354116.1 & $15 \mathrm{Rs}$ & $\begin{array}{l}\text { Lomandra } \\
\text { longifolia }\end{array}$ & Japão & D. Gonzales \\
\hline $\mathrm{H} 42$ & 01 & - & - & AG 2-2 IIIB & AJ238157.1 & 9207 & - & Japão & M. C. Julian \\
\hline
\end{tabular}

Fonte: A. Johanson, Pest Management Department, Natural Resources Institute, Central Avenue, Chatham Maritime, Chatham, Kent, ME4 4TB, Reino Unido.

A. M. Hietala, Forest Ecology, Skogforsk, Hogskoleveien 12, Aas 1432, Noruega.

D. E. Gonzáles, Sistematica Vegetal, Instituto de Ecologia, A. C., Km 2.5 Antigua Carretera a Coatepec, Xalapa, Veracruz 91000, México

E. E. Kurame, CBS, Uppsalalaan 8, NL 3584 CT Utrecht, Holanda.

G. Godoy-Lutz, Plant Pathology, University of Nebraska-Lincoln, 406 Plant Sciences Hall, Lincoln, NE 68583-0722, EUA.

H. Gronberg, Department of Biosciences, University of Helsinki, Viikki Biocenter, P.O.Box 56, Viikinkaari 9, FIN-00014, Finlândia.

M. C. Julian, Biotecnologia Microbiana,Centro Nacional de Biotecnologia CNB-CSIC, Campus Cantoblanco UAM, Madrid 28049, Espanha.

M. Hyakumachi, Gifu University, Faculty of Agriculture; Yanagido 1-1, Gifu, Gifu, 501-1193, Japão.

R. C. Fenille, Ministério da Agricultura, Goiás, Brasil.

S. Kuninaga, Health Sciences University of Hokkaido; Tohbetsu, 1757, Ishikari-gun, Hokkaido 061-0293, Japão.

V. Rubio, Biotecnologia Microbiana, Centro Nacional de Biotecnologia, Campus Cantoblanco-UAM, Madrid 28049, Espanha. 
Tabela 2. Caracterização de haplótipos Amazônicos de Rhizoctonia solani AG 2-2 (subgrupo associado a Hevea brasiliensis) de acordo com sítios polimórficos (substituições) e eventos de inserção e perda detectados em seqüências de DNA da região ITS1-5.8S-ITS2 do rDNA ${ }^{\text {a }}$.

\begin{tabular}{|c|c|c|c|c|c|c|c|c|c|c|c|c|c|}
\hline $\begin{array}{l}\text { Posição ao longo da } \\
\text { região }\end{array}$ & & & $\approx$ & 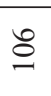 & $\underline{n}$ & $\underset{0}{\infty}$ & $\stackrel{\infty}{\approx}$ & $\stackrel{\infty}{\curvearrowright}$ & $\underset{n}{\stackrel{0}{2}}$ & 守 & $\hat{n}$ & $\begin{array}{l}\infty \\
i n \\
n\end{array}$ & ช్రి \\
\hline Número do sítio & & & - & N & $m$ & $\nabla$ & $n$ & 6 & $r$ & $\infty$ & $a$ & 으 & $=$ \\
\hline Tipo de caráter & & & $\mathrm{i}$ & $\mathrm{i}$ & - & - & $\mathrm{i}$ & - & - & - & $\mathrm{i}$ & - & - \\
\hline Consenso & & & A & $\mathrm{T}$ & $\mathrm{T}$ & $\mathrm{C}$ & G & $\mathrm{C}$ & $\mathrm{T}$ & $\mathrm{C}$ & $\mathrm{C}$ & $\mathrm{T}$ & $\mathrm{T}$ \\
\hline H46 A & 28 & 0.19 & G & $\mathrm{C}$ & . & . & . & . & . & . & . & . & . \\
\hline H01 B & 47 & 0.32 & . & . & . & . & A & . & . & . & $\mathrm{T}$ & . & . \\
\hline $\mathrm{H} 45 \mathrm{C}$ & 2 & 0.01 & . & $\mathrm{C}$ & $\mathrm{C}$ & $\mathrm{T}$ & . & . & . & $\mathrm{T}$ & . & . & . \\
\hline $\mathrm{H} 44 \quad \mathrm{G}$ & 13 & 0.09 & G & $\mathrm{C}$ & . & . & . & . & $\mathrm{C}$ & . & . & . & . \\
\hline $\mathrm{H} 47 \quad \mathrm{H}$ & 2 & 0.01 & $\mathrm{G}$ & $\mathrm{C}$ & . & . & . & . & . & . & . & $\mathrm{C}$ & . \\
\hline Total & 146 & & & & & & & & & & & & \\
\hline
\end{tabular}

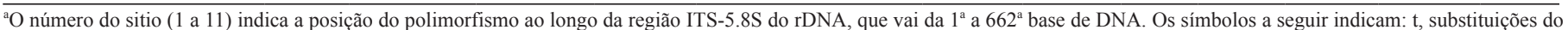

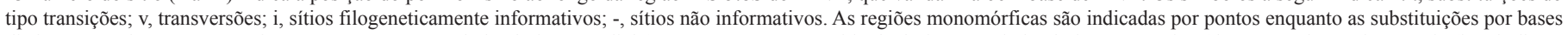

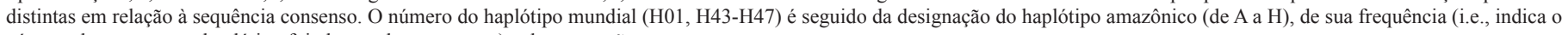
número de vezes que o haplótipo foi observado na amostra) e da proporção na amostra.

distinta em relação ao AG 2-2 IIIB, 2-2 IV e 2-2 LP.

Com base nessas observações, acreditamos ser oportuno postular que a população brasileira de T. cucumeris causando mancha areolada da seringueira e queima das folhas do maracujá, pertencentes ao grupo AG 2-2 de R. solani, compreendem um grupo de anastomose distinto do AG 2-2 IV. Assim, confirmando as observações de Gaino et al. (13), é oportuna a denominação de AG 2-2 Hb para o patógeno da mancha areolada da seringueira na Amazônia.

Há consenso sobre a utilidade e relevância da região ITS-5.8S do rDNA como marcador filogenético apropriado para identificação de grupos de anastomose de $R$. solani $(1,7,16,26)$. Por sua vez, é importante estender o estudo sobre a relação filogenética entre membros descritos do AG 2-2 (e o novo AG 2-2 Hb), incluindo informação de outros genes. Entre os genes atualmente recomendados para elucidar relações filogenéticas entre fungos basidiomicetos do gênero Rhizoctonia e correlatos, estão a subunidade maior da polimerase II de RNA (rpb2) e o fator de tradução-alongamento 1 alfa (tef1), ambos codificados nuclearmente; um gene codificado na mitocôndria, a subunidade 6 da ATP sintase (atp6); e outro gene do operon do DNA ribossômico, a subunidade grande ribossômica (LSU) (17).

Finalmente, usando o modelo coalescente, efetuamos análise evolutiva da região ITS-5.8S do rDNA da população Amazônica de $R$. solani AG 2-2 Hb da seringueira e de P. edulis (Figura 3). Na genealogia gênica construída, a direção da divergência ocorre do topo da genealogia (significando o haplótipo mais velho, ou o passado da genealogia) para a base (o haplótipo mais jovem, ou o presente). O processo coalescente vai da base (presente) ao topo (passado). Como a genealogia gênica é enraizada, todas a mutações e bifurcações estão também organizadas (ordenadas) do topo para a base. Os números abaixo de cada ramo da árvore denominam (em ordem) cada haplótipo Amazônico distinto (de A a H), sua frequência total (i.e., o número total de ocorrências do haplótipo na amostra populacional) e a frequência de cada haplótipo nas amostras de Xapuri,
Belém e Manaus (Figura 3).

Assim, com base na análise evolutiva coalescente da região ITS-5.8S do rDNA, observou-se, inicialmente, que a população de $R$. solani AG 2-2 Hb de Belém é relativamente mais velha que as demais populações analisadas. O tempo de divergência até o ancestral comum mais antigo desta população, com a mutação número 1 na genealogia, é de cerca de 0,45 unidades evolutivas coalescentes (numa escala de 0 a 1,0). O ancestral comum de todas as três populações analisadas (indicado por conter apenas a mutação número 8 na genealogia, de T para C) está associado com isolado de $R$. solani AG 2-2 Hb do maracujá, em Benevides (próximo a Belém) e tem cerca de 0,8 unidades evolutivas coalescentes de idade.

Nenhum haplótipo da região ITS-5.8S do R. solani AG 2-2 Hb amostrado em Belém foi observado em outras regiões. Entretanto, a população de Manaus compartilhou dois, de seus quatro haplótipos, com aqueles observados em Xapuri / Rio Branco, no Acre. De forma peculiar, esses haplótipos (E e B), aparecem nas duas localidades porém com freqüências diferentes em Manaus e em Xapuri / Rio Branco, indicando efeito de fluxo gênico (ou migração) e deriva genética (ou amostragem casual). Essas duas populações também compartilham um mesmo ancestral, relativamente mais jovem que o da população de Belém, com cerca de 0,2 unidades evolutivas coalescentes.

Apesar de T. cucumeris da mancha areolada da seringueira ser patógeno de parte aérea com infecção primária ocorrendo por basidiósporos dispersos a curtas e média distância (15), a hipótese de fluxo gênico a longa distância (de milhares de quilômetros) entre essas populações do patógeno parece ser de difícil aceitação, se considerarmos apenas os aspectos da biologia da mancha areolada da seringueira. Entretanto, há relato histórico de que a cultura da seringueira foi estabelecida no Acre por introdução de mudas obtidas do Amazonas (24). A dispersão do patógeno associado a mudas contaminadas e sua introdução no Acre mediada pela atividade humana, 


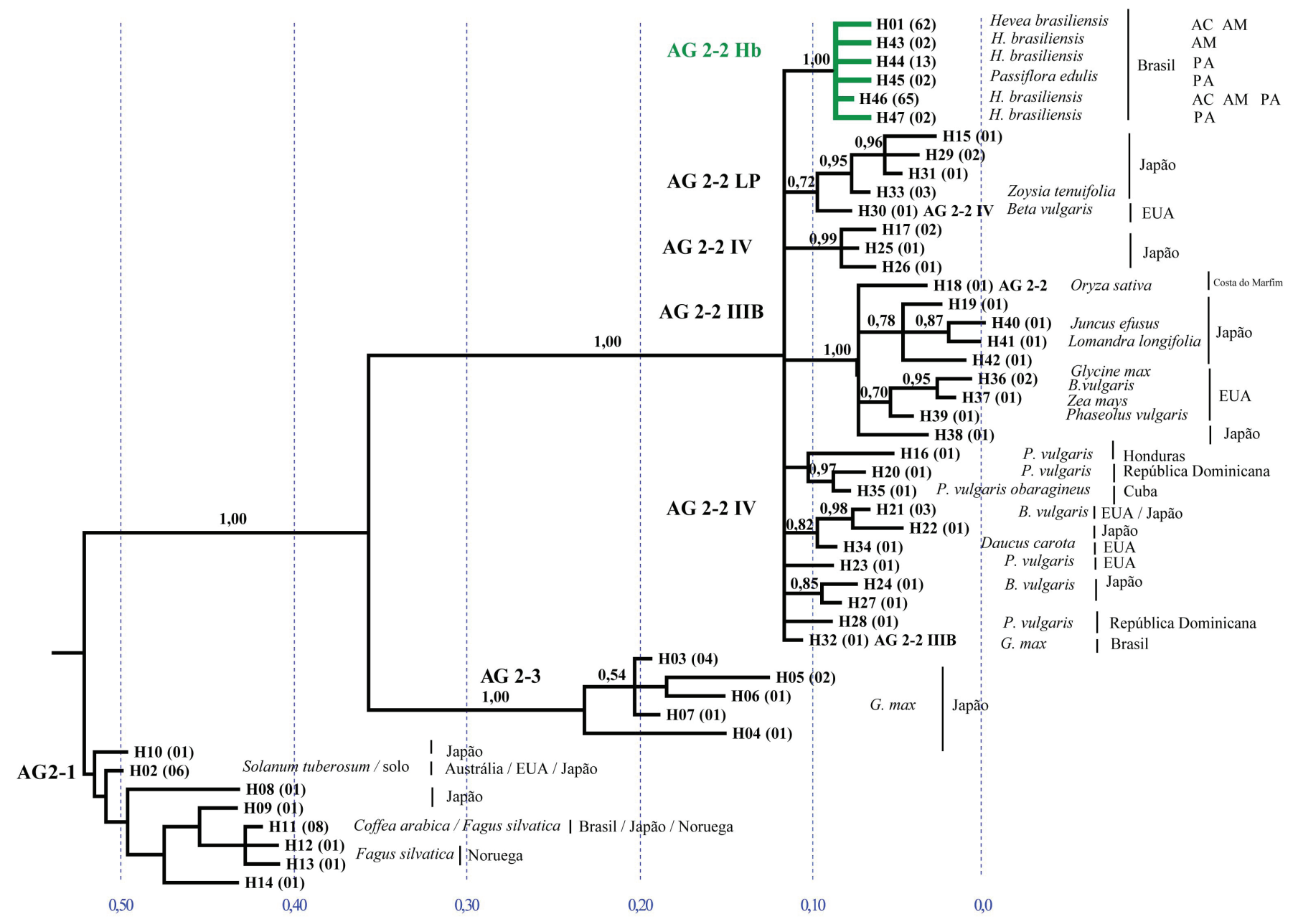

Substituições por sítio

Figura 2. Árvore ilustrando as relações filogenéticas entre haplótipos da região ITS-5.8S dos grupos AG 2-1, AG 2-2 (IIIB e IV e LP), AG 2-3 e o grupo de isolados de Rhizoctonia solani obtidos de Hevea brasiliensis e de Passiflora edulis na Amazônia brasileira a .

${ }^{a}$ Estas relações filogenéticas foram baseadas no modelo GTR + I de evolução de bases de DNA. Valores de probabilidades posteriores (variando de 0 a 1,0) geradas por análise Bayesiana de MCMCMC são apresentados para os ramos principais. Valores próximos a 1,0 indicam elevada significância estatística para o respectivo ramo, avaliada em 11542 árvores artificialmente geradas. A árvore foi enraizada usando seqüências da região ITS-5.8S do rDNA de R. solani AG 2-1. Os taxa são identificados pelo código do haplótipo mundial, seguido pelo tamanho da amostra, hospedeiro e local de origem. As seqüências da região ITS-5.8S dos diferentes grupos de anastomose utilizadas para inferir as relações filogenéticas são oriundas do NCBI/GenBank. A designação de haplótipos mundiais de $R$. solani AG 2 é apresentada na Tabela 1.

corroboraria nossas observações.

Este estudo representa uma iniciativa pioneira em análise evolutivopopulacional de um fungo fitopatogênico do gênero Thanatephorus num patossistema tropical na região Amazônica. Por sua vez, para maior robustez na descrição de padrões e interpretação de processos evolutivos que moldaram a estrutura populacional do patógeno da mancha areolada da seringueira, é necessário o desenvolvimento de um conjunto maior de marcadores genético-moleculares mais apropriados, que sejam altamente variáveis e seletivamente neutros (1). O desenvolvimento de novos marcadores de importância para estrutura genética de populações, tais como de sequências simples repetidas (SSR ou microssatélites) ou polimorfirmos de nucleotídeos únicos (SNPs), fazem parte de nossos planos para estudo das forças evolutivas moldando a estrutura populacional de $T$. cucumeris na
Amazônia. Os riscos evolutivos de T. cucumeris, por exemplo, para superar a resistência genética da clones novos de seringueira são conhecidos apenas hipoteticamente, pois se desconhece qual a importância da recombinação e do fluxo gênico moldando a estrutura populacional do patógeno.

\section{AGRADECIMENTOS}

Agradecemos à Fundação de Amparo à Pesquisa do Estado de São Paulo pelo apoio financeiro, pela concessão de auxílio-pesquisa (a P.C. Ceresini, Processo FAPESP 2004/02127-9); à CAPES e à FAPESP pela concessão de bolsa de mestrado a M.A. Basseto, S.N.C. Vicentini (FAPESP 2017/034030), ambos do programa de pós-graduação em Agronomia da UNESP Campus 


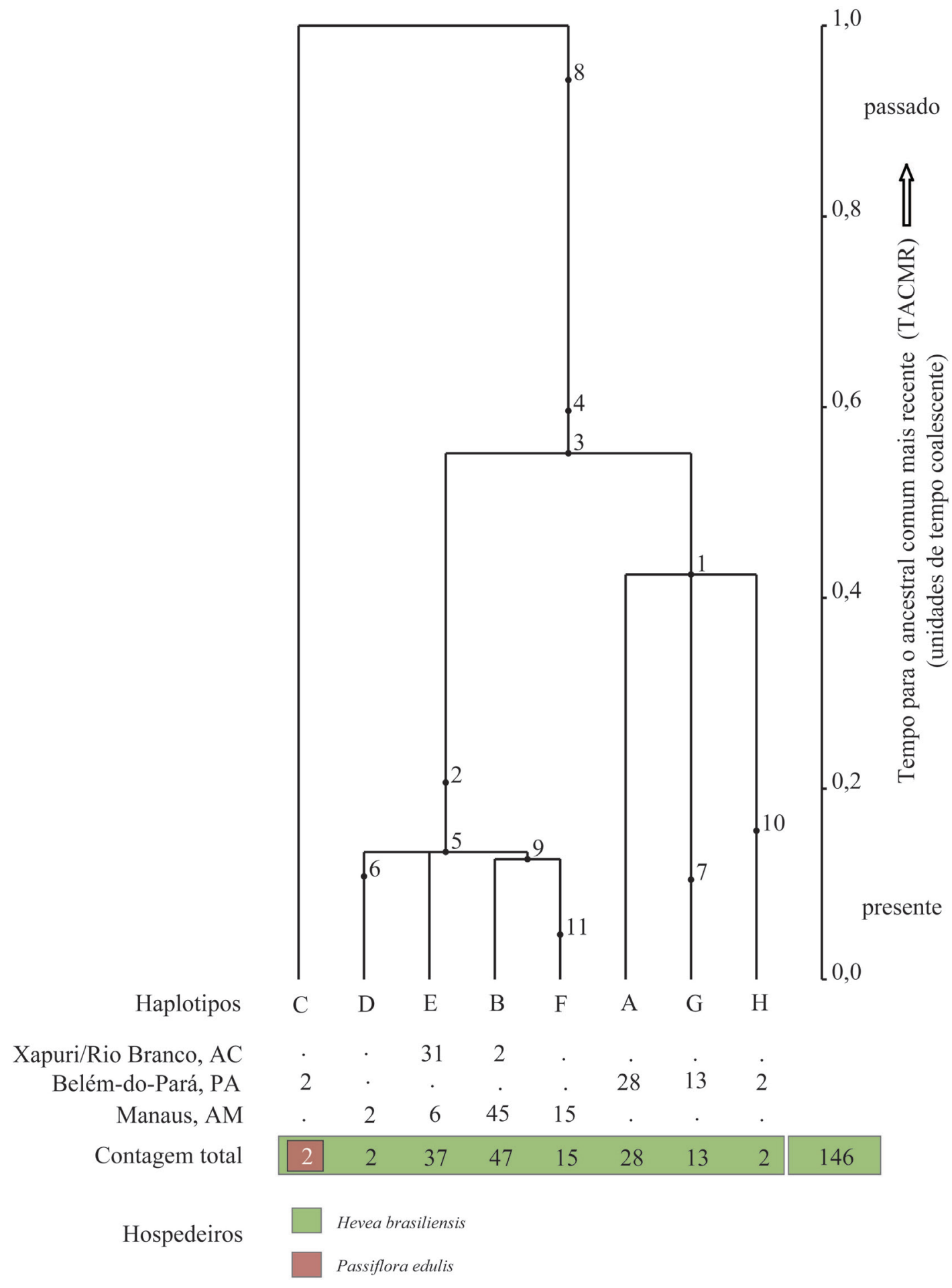

Figura 3. Genealogia gênica coalescente com a mais alta probabilidade (verossimilhança $=1.7465 \times 10^{-293}$, desvio padrão $=0.0000$ ) mostrando a distribuição de mutações (pontos pretos ao longo da genealogia) na região ITS-5.8S do rDNA em populações de Thanatephorus cucumeris (Rhizotonia solani) da mancha areolada da seringueira obtidas em Xapuri (AC), Belém (PA) e Manaus (AM) na região Amazônica a .

${ }^{a}$ As simulações do processo coalescente foram baseadas em estimador de Watson para $\Theta=0,75$ e populações de tamanho constante. A escala de tempo é expressa em unidades coalescentes. Na genealogia gênica a direção da divergência ocorre do topo da genealogia (significando o haplótipo mais velho, ou o passado) para a base (o haplótipo mais jovem, ou o presente). O processo coalescente vai da base (presente) ao topo (passado). Como a genealogia gênica é enraizada, todas a mutações e bifurcações estão também ordenadas do topo para a base. Os números abaixo de cada ramo da árvore denominam (em ordem) cada haplótipo Amazônico distinto (de A a H), sua freqüência total (i.e., o número total de ocorrências do haplótipo na amostra populacional) e a freqüência de cada haplótipo nas amostras de Xapuri, Belém e Manaus. 
de Ilha Solteira; à Embrapa Amazônia Oriental, Amazônia Ocidental e Acre que nos ofereceram suporte logístico e laboratorial para coleta e isolamento de material e ao ETH Zürich por financiar parcialmente esta pesquisa (processo TH-16/06-1, a PC Ceresini) por meio do Convênio Unesp - ETH entre 2005 e 2010. Agrademos ao apoio técnico oferecido por Marcello Zala do ETH Zürich na coleta de dados de sequenciamento de DNA.

\section{REFERÊNCIAS}

1. Arakawa, M.; Inagaki, K. Molecular markers for genotyping anastomosis groups and understanding the population biology of Rhizoctonia species. Journal of General Plant Pathology, Tokyo, v.80, p.401-407, 2014.

2. Aylor, D.L.; Price, E.W.; Carbone, I. SNAP: Combine and Map modules for multilocus population genetic analysis. Bioinformatics, Oxford, v.22, p.1399-1401, 2006.

3. Bahlo, M.; Griffiths, R.C. Inference from gene trees in a subdivided population. Theoretical Population Biology, San Diego, v.57, p.79-95, 2000.

4. Beerli, P.; Felsenstein, J. Maximum likelihood estimation of a migration matrix and effective population sizes in n subpopulations by using a coalescent approach. Proceedings of the National Academy of Sciences of the United States of America, Washington, v.98, n.8, p.4563-4568, 2001.

5. Bolkan, H.A.; Ribeiro, W.R.C. Anastomosis groups and pathogenicity of Rhizoctonia solani isolates from Brazil. Plant Disease, Chichester, v.69, p.599-601, 1985.

6. Campos, A.P.; Ceresini, P.C. Caracterização de Thanatephorus cucumeris associada à seringueira e mimosa na região Amazônica. Fitopatologia Brasileira, Brasília, v.29, p.326-327, 2004

7. Carling, D.E.; Kuninaga, S.; Brainard, K.A. Hyphal anastomosis reactions, rDNA-Internal Transcribed Spacer sequences, and virulence levels among subsets of Rhizoctonia solani Anastomosis Group-2 (AG-2) and AG-BI. Phytopathology, St. Paul, v.92, n.1, p.43-50, 2002.

8. Carpenter, J.B. Target leaf spot of the Hevea rubber tree in relation to host development, infection, defoliation and control. Washington, D.C.: USDA, 1951. (Technical Bulletin, 1028).

9. Ceresini, P.C. Rhizoctonia como fitopatógeno: biologia e diversidade de Rhizoctonia solani em agroecossistemas tropicais e perspectivas de manejo da rizoctoniose usando resistência de plantas. In: Freitas, A.S.; Dornelas, G.A.; Silva, J.C.P.; Salum, L.A.; Pimenta, L.; Pedroso, L.A.; Faria, M.D.R.; Paula, P.V.A.A.; Martins, S.A. (Ed.). Sanidade de raízes. São Carlos: Suprema Gráfica e Editora, 2014. p.177-190.

10. Chee, K.H.; Wastie, R.L. The status and future prospects of rubber diseases in tropical America. Review of Plant Pathology, Oxfordshire, v.59, n.12, p.541-548, 1980 .

11. Deslandes, J.A. Observações fitopatológicas na Amazônia. Boletim Fitossanitário, Rio de Janeiro v.1, p.202-203, 1944.

12. Ferreira, F.A.; Gasparotto, L. Mancha areolada da seringueira. In: Ferreira, F.A. (Ed.). Patologia florestal: principais doenças florestais no Brasil. Viçosa: Sociedade de Investigações Florestais, 1989. v.1, p.326-332.

13. Gaino, A.P.S.C.; Basseto, M.A.; Gasparotto, L.; Poltronieri, L.S.; Ceresini, P.C. Inferência filogenética revela a complexa etiologia das manchas areolada e foliar em seringueira e em outras espécies cultivadas na Amazônia. Acta Scientiarum. Agronomy, Maringá, v.32, p.385-395, 2010.

14. Gasparotto, L.; Kano, C.; Ceresini, P.C.; Pereira, J.C.R.; Cardoso, M.O.;
Pereira, D.A.S.; Castroagudín, V.L. Web blight (Thanatephorus cucumeris): a new disease on leaves of okra plants. Arquivos do Instituto Biológico, São Paulo, v.84, p.1-4, 2017.

15. Gasparotto, L.; Trindade, D.R.; Lieberei, R. Sistema de avaliação da incidência da mancha areolada [Thanatephorus cucumeris (Frank) Donk] em seringueira (Hevea spp.). Fitopatologia Brasileira, Brasília, v.7, n.3, p.349-357, 1982.

16. Gonzalez, D.; Carling, D.E.; Kuninaga, S.; Vilgalys, R.; Cubeta, M.A. Ribosomal DNA systematics of Ceratobasidium and Thanatephorus with Rhizoctonia anamorphs. Mycologia, New York, v.93, n.6, p.1138-1150, 2001.

17. Gónzalez, D.; Rodriguez-Carres, M.; Boekhout, T.; Stalpers, J.; Kuramae, E.E.; Nakatani, A.K.; Vilgalys, R.; Cubeta, M.A. Phylogenetic relationships of Rhizoctonia fungi within the Cantharellales. Fungal Biology, Oxford, v.120, n.4, p.603-619, 2016.

18. Hudson, R.R.; Boos, D.D.; Kaplan, N.L. A statistical test for detecting geographic subdivision. Molecular Biology and Evolution, Oxford, v.9, p.138-151, 1992.

19. Hudson, R.R.; Slatkin, M.; Maddison, W.P. Estimation of levels of gene flow from DNA sequence data. Genetics, Rockville, v.132, n.2, p.583-589, 1992.

20. Huelsenbeck, J.P.; Ronquist, F. MRBAYES: Bayesian inference of phylogenetic trees. Bioinformatics, Oxford, v.17, n.8, p.754-5, 2001.

21. Johnson, M.; Zaretskaya, I.; Raytselis, Y.; Merezhuk, Y.; Mcginnis, S.; Madden, T.L. NCBI BLAST: a better web interface Nucleic Acids Research, Oxford, v.36, p.W5-W9, 2008. Supplement 2.

22. Monacell, J.T.; Carbone, I. Mobyle SNAP Workbench: a web-based analysis portal for population genetics and evolutionary genomics. Bioinformatics, Oxford, v.30, n.10, p.1488-1490, 2014

23. Naito, S. Basidiospore dispersal and survival. In: Sneh, B.; Jabaji-Hare, S.; Neate, S.; Dijst, G. (Ed.). Rhizoctonia species: taxonomy, molecular biology, ecology, pathology and disease control. Dordrecht: Kluwer Acah demic, 1996. p.197-205.

24. Pontes, C.J.D.F. O primeiro ciclo da borracha no Acre: da formação dos seringais ao grande colapso. South American Journal of Basic Education, Technical and Technological, Rio Branco, v.1, n.1, p.107-123, 2014.

25. Posada, D.; Crandall, K.A. MODELTEST: testing the model of DNA substitution. Bioinformatics, Oxford, v.14, n.9, p.817-818, 1998.

26. Sharon, M.; Kuninaga, S.; Hyakumachi, M.; Naito, S.; Sneh, B. Classification of Rhizoctonia spp. using rDNA-ITS sequence analysis supports the genetic basis of the classical anastomosis grouping. Mycoscience, Nonoichi, v.49, p.93-114, 2008.

27. Sneh, B.; Burpee, L.; Ogoshi, A. Identification of Rhizoctonia species. Saint Paul: The American Phytopathological Society, 1991. 133p.

28. Taylor, J.W.; Jacobson, D.J.; Kroken, S.; Kasuga, T.; Geiser, D.M.; Hibbett, D.S.; Fisher, M.C. Phylogenetic species recognition and species concepts in fungi. Fungal Genetics and Biology, San Diego, v.31, n.1, p.21-32, 2000.

29. Thompson, J.D.; Gibson, T.J.; Plewniak, F.; Jeanmougin, F.; Higgins, D.G. The CLUSTAL X windows interface: flexible strategies for multiple sequence alignment aided by quality analysis tools. Nucleic Acids Research, Oxford, v.25, n.24, p.4876-82, 1997.

30. White, T. J.; Bruns, T.; Lee, S.; Taylor, J. Amplification and direct sequencing of fungal ribosomal RNA genes for phylogenetics. In: Innis, M.; Gelfand, D.; Sninsky, J.; White, T. (Ed.). PCR protocols: a guide to methods and applications. New York: Academic Press, 1990. p.315-322. escrever os autores no modelo sobrenome, prenomes abreviados 